\title{
O ensino da ética ao profissional de saúde na USP: a formação ética do terapeuta ocupacional
}

\section{Teaching ethics to the health professional at USP: the ethical education of the occupational therapist}

\author{
Maria Helena Morgani de Almeida ${ }^{1}$ \\ Maria do Carmo Castiglioni ${ }^{2}$
}

\begin{abstract}
ALMEIDA, M. H. M.; CASTIGLIONI, M. C. O ensino da ética ao profissional de saúde na USP: a formação ética do terapeuta ocupacional. Rev. Ter. Ocup. Univ. São Paulo, v. 16, n. 2, p. 75-81, maio./ ago., 2005.

RESUMO: O presente artigo se propõe a refletir sobre o conteúdo da disciplina de ética profissional oferecida atualmente pelo Curso de Terapia ocupacional da USP a partir da reforma curricular do Curso em 2001 e do conteúdo específico previsto pelos Cursos da USP na área de saúde. As autoras inicialmente conceituam os campos temáticos da "Ética", "Bioética" e "Ética Profissional", que consideram relevantes para a formação ética em saúde na atualidade. Em seguida apresentam levantamento realizado no Sistema "Jupiterweb", entre março e abril de 2005, de disciplinas oferecidas por Cursos na área de saúde. A partir da análise de conteúdo das disciplinas, identificam e reafirmam a relevância dos campos temáticos apresentados além de "Outros temas", envolvendo Direito, Administração e Legislação Sanitária. Cursos como os de Fonoaudiologia, Terapia Ocupacional e Fisioterapia contemplam os três principais campos temáticos. A ampliação do referencial teórico para além dos códigos de ética se justifica pelas múltiplas necessidades da população atendida por estes profissionais, pela complexidade do conceito de saúde que vem sendo adotado e pelo envolvimento dos profissionais da reabilitação em situações limites que passaram a compor seu cotidiano. Salientam as autoras que a atuação profissional em saúde requer combinação cuidadosa de conhecimentos técnicos e respeito aos valores humanos, ameaçados pela desigualdade social e de acesso a serviços como os de saúde e educação. A organização da disciplina de ética profissional do Curso de TO nestes três campos temáticos têm possibilitado aos estudantes refletirem sobre seu comprometimento ético em experiências pregressas, atuais e em ações profissionais futuras.
\end{abstract}

DESCRITORES: Ética. Bioética. Ética Profissional/educação. Terapia Ocupacional/ética.

\footnotetext{
${ }^{1}$ Professora Doutora do Departamento de Fisioterapia, Fonoaudiologia e Terapia Ocupacional da FMUSP. Doutora em Saúde Pública pela FSP/USP. E-mail: hmorgani@usp.br

${ }^{2}$ Professora Doutora do Departamento de Fisioterapia, Fonoaudiologia e Terapia Ocupacional da FMUSP. Doutora em Psicologia Social pela PUC/SP. E-mail: carminha_cas@hotmail.com

Endereço para correspondência: Departamento de Fisioterapia, Fonoaudiologia e Terapia Ocupacional da FMUSP. Rua Cipotânea, 51. 05360-000. São Paulo, SP. E-mail: centroto@usp.br
} 


\section{INTRODUÇÃO}

$\mathrm{C}$

om a finalidade de refletirmos sobre o conteú do específico oferecido pelo Curso de Terapia Ocupacional (TO) da USP para a formação ética de seus futuros profissionais, partimos do marco da Reforma Curricular de 2001 do Curso de TO e mapeamos o conteúdo previsto por outros Cursos oferecidos na USP da área de saúde com o mesmo propósito.

O Curso de TO da USP procurou, com base nas Diretrizes Curriculares, responder às necessidades de formação do terapeuta ocupacional, de acordo com as novas tendências que compõem o campo.

Migramos do modelo biomédico, da prática de uma reabilitação voltada para a adaptação do sujeito a uma realidade, em direção a um modelo em construção, mais abrangente através do qual se busca compreender a saúde em sua articulação com as ciências humanas e, a relação entre o sujeito e a realidade numa perspectiva dialética.

Em termos operacionais, na reestruturação curricular optamos por reduzir e condensar os créditos referentes aos conteúdos da área de biológicas e ampliar os conteúdos da área de humanas garantindo assim, carga horária equivalente.

Contudo, se nos limitarmos a apresentar somente esse resultado simplificaremos todo o processo uma vez que nos pautamos em princípios e foram as discussões produzidas que revelam a tonalidade ética da proposta; como também, o desafio em equacionar compreensão da realidade sócio-histórica e intervenção técnica.

Em outras palavras, somos chamados a responder qual a ação do terapeuta ocupacional diante do outro que experimenta cotidianamente as adversidades provocadas pela pobreza; pelas condições precárias de trabalho, moradia, alimentação; e também pelas práticas ineficazes de saúde e educação. Enfim, qual a ação do terapeuta ocupacional diante do outro que vivencia a desigualdade social que o coloca na situação de ser considerado como inferior, desqualificado, desfiliado, excluído, o que gera profundo sofrimento que se manifesta de diversas formas. Outra estratégia utilizada na reforma foi deslocar as disciplinas práticas do $5^{\circ}$ para o $4^{\circ}$ semestre. Esta organização, não prevista anteriormente, permite que o aluno conheça e estabeleça contato mais cedo com a população e, possa principalmente a partir de suas reflexões, contribuir para elaboração e desenvolvimento de planos de intervenção.

A formação em Terapia ocupacional, compreendida em um dos seus vieses, como um preparo para a profissão, não pode ficar meramente restrita ao ensino técnico. Deve se ampliar para uma formação crítica, ético-política, que ensina a perguntar, a questionar e, portanto, a produzir permanentemente novos conhecimentos.

Esse conjunto de mudanças possibilitou então a geração de hipóteses para a interpretação da realidade e estas foram alimentando discussões nas disciplinas aplicadas e de conteúdo específico e fomentadas sistematicamente na disciplina de Ética Profissional, confirmando que a ética é histórica e aflora como condição necessária à vida humana (SAWAIA, 1999).

Dessa forma, embora na Reforma Curricular a disciplina Ética Profissional não tenha sofrido alteração em sua ementa, na prática ela vem sendo forjada, gradativamente, para ser capaz de abarcar aspectos que efetivamente ampliem e enriqueçam a ação do terapeuta ocupacional. Fez-se necessário para tanto a construção de um eixo teórico e conceitual que sustentasse e amparasse questionamentos éticos sobre práticas profissionais vigentes. A articulação de temas de "Ética", "Bioética" e "Ética Profissional" nos parece se constituir em pilar desta construção. Estes temas têm orientado discussões em sala de aula que refletem a busca pelo comprometimento ético dos futuros profissionais de TO.

Entendemos "Ética" enquanto possibilidade para reflexão sobre costumes ou ações humanas uma vez que, segundo Vasques (2002) e Valls (2004), "Ética" constituise como a ciência do comportamento moral dos homens em sociedade. A "Ética" nos convida a refletir sobre a distinção entre o bem e o mal, a questão da consciência, do valor, da lei e dos ideais éticos de liberdade e justiça social, e nos ampara para discutirmos sua aplicação às questões específicas e concretas como as da "Bioética" e da "Ética Profissional".

Segundo Segre e Cohen (1995) a "Bioética" refere-se a parte da ética que enfoca questões referentes a vida humana.

De acordo com Potter (1971) citado por Diniz e Guilhem (2002) a Bioética refere-se a disciplina capaz de acompanhar o desenvolvimento científico com uma vigilância ética que possa estar isenta de interesses morais, a fim de que a aplicação do conhecimento científico não resulte em desrespeito aos valores humanos. Seu grande propósito é colocar-se como instância mediadora e democrática para os conflitos avivados pela paradoxal situação em que a medicina está cada vez melhor 
e os pacientes estão cada vez pior, especialmente os pobres (DINIZ; GUILHEM, 2002)

Segundo Garrafa (1995) a "Bioética" pode ser considerado um movimento que se ocupa das situações de vida cotidianas - fome, abandono, exclusão social, má distribuição de recursos, racismo; e situações-limite ou de fronteira decorrentes do desenvolvimento científico e tecnológico, apresentando-se como a procura de um comportamento responsável por parte dos profissionais que decidem e desenvolvem ações em saúde e pesquisa com seres humanos.

Pensar a "Ética Profissional" dos profissionais da saúde, inclusive do TO é pensar principalmente a ética aplicada à vida ou à "Bioética".

Os códigos de ética correspondem ao campo do "dever", constituindo-se em um conjunto de normas que indicam como devem se comportar indivíduos que compartilham a característica de associação a determinado corpo sócio-profissional e, por integrar o campo do Direito "não exigem convicção pessoal às suas normas, pois elas são obrigatórias, impostas e comportam coerção estatal" (FORTES, 1998, p. 28).

Para que na aplicação dos códigos se reflitam as convicções pessoais e profissionais e necessidades dos usuários destes serviços estes códigos deveriam preferencialmente ser elaborados e oportunamente revistos por todos os envolvidos a fim de se constituírem instrumentos legítimos de facilitação de práticas profissionais que tenham compromisso de vida e com a vida.

Segundo Passos (1993) para que os códigos profissionais reflitam a ética e não sejam instrumentos de interesse exclusivo de categorias profissionais "devem enfrentar as práticas tradicionais inadequadas, devem estar abertos ao novo, a revisão constante pois assim eles se tornarão verdadeiras práticas deontológicas“( (p. 62).

\section{OBJETIVOS}

O presente artigo se propõe a refletir sobre o conteúdo da disciplina de ética profissional oferecida atualmente pelo Curso de Terapia ocupacional da USP, a partir de referenciais como a reforma curricular do Curso de TO de 2001 e o conteúdo previsto pelos Cursos oferecidos na USP na área da saúde para a formação ética profissional. O propósito maior do artigo é explicitar, por essa via eleita, o caminho que estamos trilhando para a formação ética dose futuros profissionais.

\section{PROCEDIMENTOS}

Para apreensão de conteúdo específico sobre ética oferecido nos diversos Cursos, foi realizada pesquisa no Sistema "JupiterWeb" entre março e abril de 2005. As consultas às disciplinas foram feitas através dos termos: ética, bioética, ética profissional e deontologia. Podemos afirmar que a busca pelas disciplinas a partir desta nomenclatura foi exaustiva.

Selecionamos algumas informações sobre as "disciplinas oferecidas" que julgamos pudessem nos oferecer subsídios para uma análise comparativa sucinta entre a formação ética pretendida pelo Curso de TO e aquela pretendida pelos demais Cursos. As informações selecionadas foram: número de disciplinas por Curso, número de créditos por disciplina e conteúdo programático de cada uma delas. Vale salientar que para uma parte das disciplinas, o programa resumido trouxe informações suficientes sobre o conteúdo, enquanto que para outras, recorremos ao programa extenso.

Desenvolvemos a análise de conteúdo do conjunto das disciplinas, a partir da identificação e organização sucinta, de campos temáticos por elas contemplados.

\section{RESULTADOS E DISCUSSÃO}

Os temas desenvolvidos pelo conjunto das disciplinas, incluindo aqueles oferecidos pela disciplina de "Ética Profissional" do Curso de TO, foram organizados, em sua maior parte, em campos temáticos que compreendemos como relevantes à formação ética dos distintos profissionais na área de saúde na atualidade como: "Ética", "Bioética" e "'Ética Profissional". Identificamos, ainda, durante o levantamento de disciplinas específicas no Sistema "JúpiterWeb", "Outros temas" que envolvem especialmente conceitos de Direito, Administração e Legislação Sanitária, entre outros.

Nosso propósito através do Quadro 1 foi apresentar, de forma sucinta, a totalidade de temas previstos nos programas oferecidos pela várias disciplinas.

É importante salientar que cada Curso contribui, a partir de suas disciplinas, de forma distinta para a composição dos campos temáticos identificados. Consideramos que a ênfase sobre um ou outro campo e mesmo a não inclusão de alguns campos temáticos estão relacionadas à subárea de conhecimento, sua relação com as demais subáreas, a população alvo de sua atenção, situação atual no mercado de trabalho e perspectivas futuras, bem como propósitos e objetivos das disciplinas que oferece. 
Quadro 1 - Apresentação sucinta de temas segundo campos temáticos - contidos em disciplinas de ética oferecidas pelos Cursos da USP na área da saúde. Sistema JupiterWeb, março e abril de 2005.

\begin{tabular}{|c|c|}
\hline Campo Temático & Temas \\
\hline E: ética & $\begin{array}{l}\text { O homem: animal biológico, racional e simbólico. Razão e consciência. A dimensão ética: pessoa e ser humano. } \\
\text { Liberdade e direitos humanos, valor e autonomia, cultura e dever, desejo e vontade, ética e psicanálise. Os } \\
\text { constituintes do campo ético, senso moral e consciência moral, juízo de fato e de valor, a pessoa autônoma, a } \\
\text { filosofia moral, o problema, a relação com os outros, ética e moral social. Distinção entre ética e moral, ética e } \\
\text { normas jurídicas, ética e normas deontológicas. Evolução do conceito de ética ou os principais sistemas éticos } \\
\text { clássicos: a ética de Aristóteles ou a ética das virtudes, a ética cristã a partir dos preceitos da antigüidade, a ética } \\
\text { kantiana ou a ética do dever, a ética contemporânea, a ética utilitarista, o pluralismo ético (ou a ética do respeito pela } \\
\text { diferença), a ética da responsabilidade, a ética do cuidado, a ética da solidariedade. Teoria utilitarista e teoria } \\
\text { deontológica da ética. }\end{array}$ \\
\hline B: bioética & $\begin{array}{l}\text { Histórico e conceito de bioética. Distinção entre Ética, Moral, Deontologia e Bioética. Autonomia e paternalismo. } \\
\text { Principais correntes da bioética: principialista, utilitarista, feminista, moralista, Kantiana, do cuidado, etc. Os pilares } \\
\text { da bioética principialista: autonomia, beneficência, não-maleficência e justiça. Bioética do cotidiano e bioética de } \\
\text { fronteira. Temas de bioética: exclusão social, violência, vulnerabilidade, humanização da assistência, reprodução } \\
\text { humana, aborto, doação e transplante de órgãos, morte, morrer e eutanásia. Ética em pesquisa com seres humanos: } \\
\text { Resolução no } 196 / 96 \text { do CNS. Princípios da Bioética: A sacralidade e a qualidade da vida. Bioética de exercício } \\
\text { profissional. O homem e a natureza: a responsabilidade pelo meio ambiente. Experimentação e uso biomédico dos } \\
\text { animais. A comunicação no processo terapêutico: o segredo profissional e a verdade ao doente. Saúde e Justiça } \\
\text { Social. A justa distribuição dos recursos na saúde. Conceituação, origem e papel das Comissões e dos Comitês de } \\
\text { Ética. Ética como qualidade das ações em Saúde: Autonomia do usuário x ação paternalista na assistência à saúde. O } \\
\text { direito a ser informado, padrões éticos de informação na assistência à saúde, a privacidade, a confiabilidade das } \\
\text { informações e o sigilo profissional na assistência e nos sistemas de informação de saúde, atestados e boletins médicos. }\end{array}$ \\
\hline $\begin{array}{l}\text { P: ética } \\
\text { profisional }\end{array}$ & $\begin{array}{l}\text { Código de ética e outros instrumentos legais referentes à atuação do profissional frente ao desenvolvimento } \\
\text { técnico e científico, responsabilidade como profissional, cientista, professor e cidadão; campo de atuação; o sigilo } \\
\text { profissional, o relatório, os honorários, a aceitação e transferência de clientes, a conclusão do trabalho. Relação } \\
\text { terapeuta-paciente-equipe-instituição-categoria profissional-sociedade: Relação Terapeuta-Paciente, Relação } \\
\text { Terapeuta-Paciente Terminal, Relação terapeuta - paciente portador de doença infecto-contagiosa,-Relações com os } \\
\text { empregadores, superiores, colegas e subordinados, outras profissões afins. Divulgação de dados. A publicidade sobre } \\
\text { serviços profissionais. A investigação científica. Conselhos profissionais: Federal e Regionais; história, composição; } \\
\text { funções; inscrição; importância para o desenvolvimento profissional. Sindicatos e associações, aspectos legais da } \\
\text { profissão: contribuições (Imposto de Renda, Imposto sobre Serviços, INSS), o profissional autônomo na relação } \\
\text { empregado x empregador; Ética e a competência: Educação e Sociedade. Responsabilidade civil e criminal. } \\
\text { Deontologia e Diceologia. Exercício lícito e ilícito da profissão: conceito, título idôneo; registros necessários; } \\
\text { exercício legal; charlatanismo, erro médico. }\end{array}$ \\
\hline O: outros temas & $\begin{array}{l}\text { Legislação sanitária e complementar. Direitos e conceitos: noções de direito e relações sociais, ramos do direito e } \\
\text { fontes do direito. Lei: classificação das leis, hierarquia das leis, formação das leis, revogação e irretroatividade. Atos } \\
\text { jurídicos. Classificação das leis. Noções de direito penal: atos ilícitos, crime doloso, crime culposo, crime } \\
\text { privilegiado, homicídio qualificado, infanticídio, aborto, genocídio, negligência, ação penal privada e pública, } \\
\text { eutanásia e omissão de socorro. Personalidade e capacidade: conceitos de pessoa física e pessoa jurídica, tipos e } \\
\text { constituição. Noções básicas do Direito. Administração Sanitária e Farmacêutica. Correntes filosóficas e sua } \\
\text { influência para o desenvolvimento do significado da Educação Física. Dimensões filosóficas da Educação Física } \\
\text { diante de questões relacionadas com valores estéticos e de linguagem. Reflexão filosófica aplicada à Educação Física Escolar. }\end{array}$ \\
\hline
\end{tabular}


Quadro 2 - Disciplinas oferecidas pelos Cursos da USP na área de saúde, segundo temas pertencentes aos campos temáticos, número de disciplinas e carga horária. Sistema JupiterWeb, março e abril de 2005.

\begin{tabular}{|c|c|c|c|}
\hline Curso & Disciplinas & Carga horária & $\begin{array}{l}\text { Temas } \\
\text { pertencentes aos } \\
\text { Campos temáticos: } \\
\text { E, B, P e O }\end{array}$ \\
\hline Psicologia - SP & Ética Profissional & $\mathrm{CA}=2 ; \mathrm{CT}=1$ & E e P \\
\hline \multirow[t]{2}{*}{ Psicologia Clínica - SP } & Ética na Clínica & $\mathrm{CA}=2 ; \mathrm{CT}=1$ & E e P \\
\hline & Ética Profissional & $\mathrm{CA}=2 ; \mathrm{CT}=1$ & $\mathrm{P}$ \\
\hline Psicologia e Educação - RP & Ética Profissional & $\mathrm{CA}=2$ & E e P \\
\hline Fonoaudiologia - BA & Ética e orientação profissional & $\mathrm{CA}=2$ & $\mathrm{P}$ \\
\hline Fonoaudiologia - SP & Ética profissional & $\mathrm{CA}=1$ & E e P \\
\hline Terapia Ocupacional - SP & Ética Profissional & $\mathrm{CA}=2$ & $\mathrm{E}, \mathrm{B}$ e $\mathrm{P}$ \\
\hline Fisioterapia - SP & Ética Profissional & $\mathrm{CA}=3$ & $\mathrm{E}, \mathrm{B}$ e $\mathrm{P}$ \\
\hline Fisioterapia e Terapia & & & \\
\hline Ocupacional - RP & Fundamentos de Bioética e Deontologia & $\mathrm{CA}=2$ & E, B e P \\
\hline \multirow[t]{3}{*}{ Enfermagem - SP } & Ética de enfermagem & $\mathrm{CA}=2$ & - \\
\hline & Ética e Legislação da Enfermagem & $\mathrm{CA}=3$ & $\mathrm{~B}$ e $\mathrm{P}$ \\
\hline & Bioética e Saúde no Cinema: Reflexão e Debate & $\mathrm{CA}=1$ & B \\
\hline \multirow{3}{*}{$\begin{array}{l}\text { Enfermagem Psiquiátrica e } \\
\text { Ciências Humanas - RP }\end{array}$} & & & \\
\hline & Bioética & $\mathrm{CA}=2$ & $\mathrm{~B}$ \\
\hline & Fundamentos de ética & $\mathrm{CA}=2$ & $\mathrm{E}$ \\
\hline \multirow[t]{2}{*}{ Farmácia -SP } & Ética em Saúde & $\mathrm{CA}=2$ & $\mathrm{~B}$ \\
\hline & Deontologia e Legislação Farmacêutica & $\mathrm{CA}=2 ; \mathrm{CT}=1$ & $\mathrm{E}, \mathrm{B}, \mathrm{P}$ e O \\
\hline Ciências farmacêuticas - RP & Deontologia e legislação & $\mathrm{CA}=3$ & $\mathrm{P}$ e O \\
\hline Odontologia social - SP & Deontologia & $\mathrm{CA}=4$ & $\mathrm{P}$ \\
\hline \multirow[t]{2}{*}{ Odontologia -BA } & Deontologia e Odontologia Legal & $\mathrm{CA}=3$ & $\mathrm{P}$ \\
\hline & Deontologia, Legislação e Odontologia Legal & $\mathrm{CA}=3$ & $\mathrm{P}$ \\
\hline Nutrição -RP & Fundamentos de Bioética e Deontologia & $\mathrm{CA}=2$ & $\mathrm{E}, \mathrm{B}$ e $\mathrm{P}$ \\
\hline \multirow[t]{2}{*}{ Medicina - RP } & Bioética Médica & $\mathrm{CA}=1$ & $\mathrm{~B}$ e $\mathrm{P}$ \\
\hline & Medicina Legal do Trabalho e Deontologia Medica & $\mathrm{CA}=5$ & - \\
\hline \multirow[t]{5}{*}{ Medicina - SP } & Bioética & $\mathrm{CA}=2$ & B e $P$ \\
\hline & Bioética Clínica & $\mathrm{CA}=2$ & $\mathrm{~B}$ \\
\hline & $\begin{array}{l}\text { Enfoque Autonomista da Bioética: a Reflexão Ética } \\
\text { sem Conceitos Aprioristicos }\end{array}$ & $\mathrm{CA}=1 ; \mathrm{CT}=1$ & E, B e P \\
\hline & Medicina Legal, Ética Medica e Medicina Social e do Trabalho & $\mathrm{CA}=7$ & - \\
\hline & Deontologia Médica & $\mathrm{CA}=2$ & - \\
\hline \multirow[t]{2}{*}{ Educação Física - SP } & Dimensões Filosóficas da Educação Física & $\mathrm{CA}=4 ; \mathrm{CT}=2$ & $\mathrm{Ee} \mathrm{O}$ \\
\hline & Dimensões Filosóficas da Educação Física escolar & $\mathrm{CA}=2$ & $\mathrm{P}$ e O \\
\hline
\end{tabular}

Legenda: SP: Campus de São Paulo; RP: Campus de Ribeirão Preto; BA: Campus de Bauru; CA: Crédito aula (15 horas); CT: Crédito trabalho (30 horas); E: Ética; B: Bioética; P: Ética Profissional; O: Outros temas 


\section{DISCUSSÃO}

O Curso com o maior número de disciplinas é o de Medicina - SP com 5 disciplinas e 14 créditos-aula, seguido por Enfermagem - SP com 3 disciplinas e 6 créditos-aula. Estes Cursos têm destinado boa parte de sua carga horária ao campo temático da "Bioética" tanto em disciplinas que combinam campos quanto em disciplinas específicas. A ênfase sobre este campo temático está relacionada ao fato destes profissionais lidarem cotidianamente com os limites da vida (nascimento e morte) e enfrentarem com mais freqüência que outros profissionais da área de saúde situações extremas ou limites e que os têm suscitado a refletir sobre questões como curar e cuidar, sacralidade e qualidade de vida, autonomia e paternalismo, alocação de recursos em saúde, dentre outros.

Com 2 disciplinas e 4 créditos-aula temos os Cursos de Farmácia - SP e Psicologia Clínica - SP. Quanto aos Cursos de Odontologia - BA, Medicina-RP e Educação Física-SP, embora ofereçam 2 disciplinas, o fazem com um maior número de créditos ( 6 créditos-aula). Estes cursos têm desenvolvido temas diversos, observa-se, no entanto, ênfase em conteúdos de "Ética profissional" pelos Cursos de Psicologia Clinica - SP e Odontologia - BA. Conforme previsto, os Cursos de Farmácia - SP e Medicina - RP, destinam créditos em disciplinas, específicas ou não, para o desenvolvimento do campo temático da "Bioética" pelas exigências próprias destas áreas.

Os Cursos de Psicologia - SP e RP, Ciências farmacêuticas - SP, Odontologia - SP, Fonoaudiologia - SP e BA, concentram atenção em conteúdos de "Ética" e "Ética profissional" enquanto Terapia Ocupacional - SP e RP, Fisioterapia - SP e RP e- Nutrição-RP contemplam conteúdos dos três principais campos temáticos. Vale frisar que todos estes cursos têm buscado desenvolver os conteúdos apresentados através de uma única disciplina com carga horária de 1 a 3 créditos-aula.

Este panorama nos remete a uma reflexão sobre as múltiplas necessidades da população que demanda a atenção de profissionais da área de reabilitação e que requerem não uma intervenção exclusivamente técnica e que vise, como dissemos anteriormente, a adaptação do sujeito a uma dada realidade, mas uma intervenção fundamentada na compreensão da saúde em sua complexidade e pautada, antes de tudo, em respeito aos valores humanos, valores estes que se encontram especialmente ameaçados por questões como desigualdade social, dificuldade de acesso à saúde, especialmente aos recursos que envolvem alta tecnologia, dificuldade de acesso à educação, trabalho, cultura e lazer.

$\mathrm{O}$ desvelamento da problemática que envolve estas e outras necessidades não se dá somente tomando-se como referência os códigos de ética profissional, requerendo referencial mais amplo, como os da "Ética" e "Bioética". Esta gama de referenciais se justifica também para amparar reflexões sobre situações limites que passaram, mais recentemente, a compor o cotidiano de profissionais de reabilitação, que se vêem, por exemplo, envolvidos com pacientes terminais e outros sujeitos de seu entorno.

Os conteúdos de "Ética profissional" desenvolvidos pelo Curso de TO, em sua disciplina específica compreendem reflexões sobre o Código de Ética e outros instrumentos legais, o papel dos Conselhos Federal, Regionais e Associações de Classe, as exigências requeridas pelo mercado de trabalho para a inserção profissional e os possíveis vínculos de trabalho a serem estabelecidos, bem como sobre a relação com empregadores, empregados, colegas de trabalho e usuários. Os conteúdos mencionados, aliados aos conteúdos de "Ética" e "Bioética" têm possibilitado aos estudantes nomearem, organizarem, enfim, se reapropriarem de experiências de práticas e estágios supervisionados, oferecidos a partir do $4^{\circ}$ semestre do Curso. Além disso, têm auxiliado os graduandos a refletirem sobre seu comprometimento ético em ações profissionais futuras.

\section{CONSIDERAÇÕESFINAIS}

Consideramos que alguns desafios se impõem aos responsáveis pelas disciplinas de ética em Cursos da área de saúde. Estas disciplinas devem reunir conceitos e informações que abarquem a diversidade de situações que requerem comprometimento ético dos futuros profissionais, na relação com o outro: a sociedade, o serviço, a categoria profissional, o colega de trabalho, o usuário.

Às disciplinas se impõe ainda o desafio de resistirem à tendência atual de desrespeito aos valores humanos imposto por uma lógica que constantemente invalida o sujeito, tornando-o mero objeto de intervenções técnicas-profissionais.

No que se refere ao Curso de TO da USP, acrescentamos que temos buscamos resgatar algumas situações reais vivenciadas pelos futuros profissionais e elaborar outras que, em conjunto, promovam o exercício da postura ética numa diversidade de situações, especialmente naquelas que envolvem o reconhecimento da interprofissionalidade como estratégia para o enfrentamento da complexidade que cerca a atenção em saúde. Mais do que introduzir para os estudantes o conceito do outro como sujeito autônomo e protagonista de sua própria história, a disciplina de "Ética Profissional" reúne e tem reforçado princípios éticos fomentados durante toda a formação, configurando-se como "locus" privilegiado para a consagração da relação entre o profissional e o outro como uma relação entre sujeitos. 
ALMEIDA, M. H. M.; CASTIGLIONI, M. C.Teaching ethics to the health professional at USP: the ethical education of the occupational therapist. Rev. Ter. Ocup. Univ. São Paulo, v. 16, n. 2, p. 75-81, maio./ago., 2005.

\begin{abstract}
S: The present article proposes a reflection on the content of the classes of professional ethics presently taught in the Occupational Therapy Course at USP based on the curricular modifactions made in 2001 and the specific content of the programs for the health courses at USP. Initially the authors evaluate the "Ethical", "Bioethical" and "Professional Ethics" thematic grounds presently considered relevant in the ethical formation in health fields. Afterwards they present a survey conducted in "Jupiterweb" System, between March and April 2005, of classes offered in Courses of the heath fields. Based on the analysis of the content of the classes, they identify and reaffirm the relevancy of the thematic grounds presented besides "other themes", involving Law, Administration and Sanitary Legislation. Courses like Occupational Therapy and Physiotherapy contemplate the three major thematic grounds. The increase of the theoretical referential is justified by the multiple needs of the population these professionals take care of, by the complexity of the health concept being adopted and by the involvement of the rehabilitation professionals in border line situations that have become part of their daily routine. The authors emphasize that professional health performance requires a careful combination of technical knowledge and respect for human values, threatened by social differences and access to services such as health and education. The organization of the professional ethics class for the Occupation Therapy course, in these three thematic grounds, has provided the students with the possibility of reflecting on their own ethical commitment in preceding and present experiences as well as future professional actions.
\end{abstract}

KEY WORDS: Ethics. Bioethics. Ethics, professional/education. Occupational therapy/ethics.

\title{
REFERÊNCIAS
}

DINIZ, D.; GUILHEM, D. O que é bioética. São Paulo: Brasiliense, 2002. (Coleção: Primeiros Passos).

GARRAFA, V. A dimensão da ética em saúde pública. São Paulo: Faculdade de Saúde Pública da USP, 1995. (Ad Saúde Série Temática 4).

PASSOS, E. S. Tendências da ética profissional na modernidade. Rev. Bras. Enferm., Brasília, v. 46. n. 10, p. 56-62, 1993.

SAWAIA, B. B. As artimanhas da exclusão: análise psicossocial e ética da desiguladade social. Rio de Janeiro: Vozes, 1999.
SEGRE, M.; COHEN, C. Bioética. 2a ed. São Paulo: EDUSP, 1995.

FORTES, P. A. C. Ética e saúde. São Paulo: E.P.U., 1998.

UNIVERSIDADE DE SÃO PAULO. Informações de disciplina [online]. 2005. Disponível em: URL: http://sistemas1.usp.br8080/ Jupiterweb/jupDisciplinaBusca?tipo=0.

VALLS, A. L. M. O que é ética. 8a ed. São Paulo: Brasiliense, 2002. (Coleção: Primeiros Passos).

VASQUEZ, A. S. Ética. 22a ed. Rio de Janeiro: Civilização Brasileira, 2002

Recebido para publicação: 10/05/2005

Aceito para publicação: 30/05/2005 